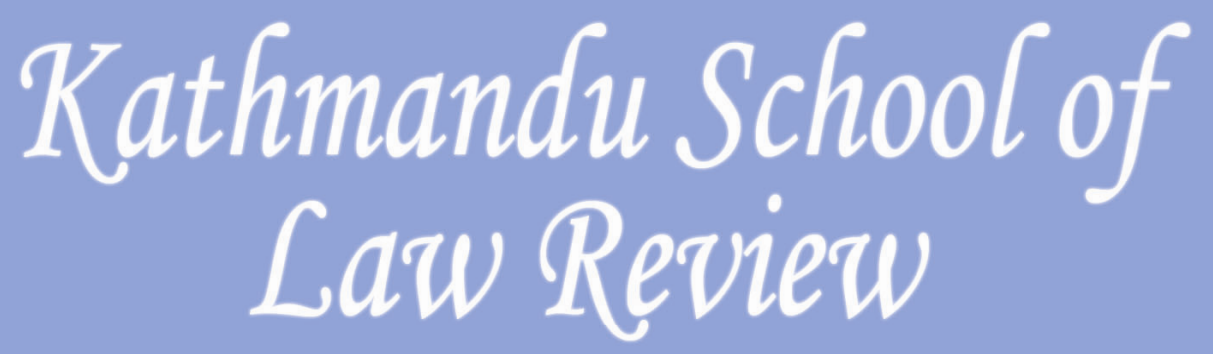

ISSN 2091-2110

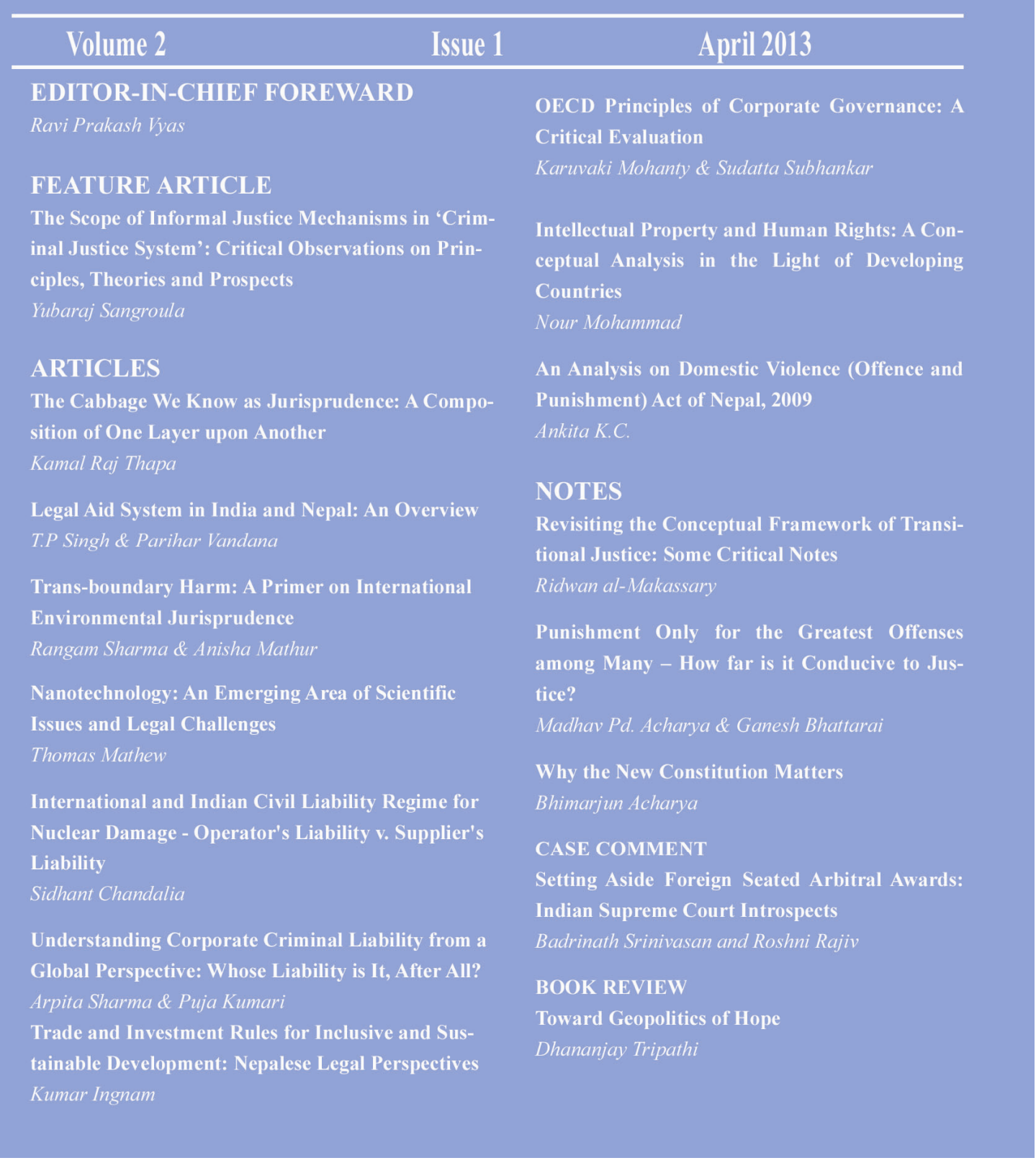




\title{
International and Indian Civil Liability Regime for Nuclear Damage - Operator's Liability v. Supplier's Liability
}

\begin{abstract}
Sidhant Chandalia ${ }^{1}$
Nuclear energy has seen tremendous growth in the last two decades and has a considerable share in world electricity supply. No nuclear reactor can be $100 \%$ safe. Every reactor has a small, but finite chance of catastrophic failure, as seen in Chernobyl, Three Mile Island, Fukushima and many smaller accidents around the world, including those in India. Nuclear projects are non-bankable in the sense that they cannot be insured. If they could, the matter would be simple enough. The nuclear plant and every person likely to be affected by radiation would be insured for a suitable sum, but the cost of a disaster and the lawsuits that would ensue make it virtually impossible to insure a nuclear power plant. Hence, there is a need to put an artificial compensation and liability mechanism in place to deal with nuclear accidents. The issue is not merely the amount of compensation to be paid in the event of an accident but also who would be encumber with the bill, the operators or the suppliers, and to what extent.
\end{abstract}

\section{Introduction}

The early years of the development of civil nuclear technology in the 1950s and 1960s were marked by public enthusiasm for new technology and the promise of cheap electric power. By the 1970s, that faith was eroding and the environmental movements were gaining importance. Nuclear accidents at Three Mile Island in March 1974 and Chernobyl in April 1986, in which 65,000 people died and the damages went as high as US $\$ 250$ billion, made the public apprehensive of nuclear energy; it was a realisation of the potential catastrophe that lies closed beneath the nuclear reactors. These accidents demonstrated that the economic, environmental and health consequences of a nuclear mishap are extremely serious. The environmental movements were giving little comfort to the public who were already fearful of the harms that would be caused to them and their family in case of nuclear accidents. However, by end of 1990s and beginning of the twenty first century, radioactivity was being replaced by global warming as more imminent and dangerous environmental threat in the public eye. Growing concern over global warming has put a veil of respectability on nuclear energy since carbon emissions from nuclear power plants are negligible. $^{2}$

$2^{\text {nd }}$ year student, the W.B. National University of Juridical Sciences, Kolkata

Savvy Soumya Misra, 'Radioactive Mirage' (2009) 2 Down to Earth, 28. 
The operation of the nuclear industry has largely proceeded routinely and without major public concern in many countries for the last two decades, producing a significant proportion of the world's energy. ${ }^{3}$ Whilst there are still very strong objections to the use of nuclear power, which have led some states to turn their backs on the continuation or expansion of a nuclear power programme, the political imperative of reducing greenhouse gas emissions, coupled with concerns over energy security, have led to a revival of interest in the development of new nuclear power facilities in various developing and developed countries around the world. ${ }^{4}$ The nuclear industry has even coined a phrase for the change in sentiments - 'nuclear renaissance'.

Nuclear energy supplies some $14 \%$ of the world's electricity. Today, 30 countries use nuclear energy to generate up to three quarters of their electricity and a substantial number of them depend on it for one quarter to one half of their entire supply. ${ }^{5}$ Some 14,500 reactor years of operational experience have been accumulated since the 1950s by the world's 435 nuclear power reactors. ${ }^{6}$

India has a total of 20 nuclear reactors in operation, generating 4,780 MW while seven other reactors are under construction and are expected to generate an additional 5,300 MW. ${ }^{7}$ Ever since the Indo-US nuclear deal signed in October 2008 lifted 34 year old global sanctions that denied India access to the international atomic energy market including uranium, India has been on a shopping spree, buying nuclear fuels and reactors. Areva is setting up two reactors of 1,650 MW each in Jaitapur in Maharashtra and deals worth US \$700 million have been signed with Russia for supplying nuclear fuel for five years; many other projects are in offing. ${ }^{8}$ India plans to increase its nuclear generation capacity to $470,000 \mathrm{MW}$ by 2050 , as announced by Prime Minister Manmohan Singh in September 2009. ${ }^{9}$

In the background of removal of global sanctions and growing energy needs of the country and increase in nuclear commerce, the Indian Parliament has passed the Civil Liability for Nuclear Damage Act 2010 to put a definite mechanism in place to deal with compensation claims arising from a nuclear accident. After the Bill was passed in Lok Sabha, PM Manmohan Singh said that the occasion signalled the 'completion of a journey to end the apartheid against India in the field of atomic power. ${ }^{10}$ However, the issue is not merely the amount of compensation to be paid in the event of an accident, but who would encumber the bill, whether the operators or the suppliers, and to what extent.

\footnotetext{
3 Stephen Tromans, Nuclear Law: The Law Applying to Nuclear Installations and Radioactive Substances in its Historic Context ( $2^{\text {nd }}$ edn, Hart Publishing 2010) 1.

$4 \quad$ Ibid.

5 World Nuclear Association, 'Nuclear Power in the World Today' <http://www.world-nuclear.org/info/ inf01.html> accessed 1 March 2013.

6 Ibid.

7 PTI, 'India's 20th nuclear power plant goes critical' The Hindustan Times (Bangalore, 27 November 2010).

$8 \quad$ Misra (n 1) 27.

9 Latha Jishnu, 'Nuclear Chimera' (2010) 2 Down To Earth , 22.

10 John Cherian, 'Safety last' (2010) 27 (19) Frontline, 28.
} 
First, this paper critically analyses the historical development of notions of liability regimes in the nuclear energy market. Then it discourses on international law in the field of civil liability for nuclear accidents. The analysis includes the Paris Convention of 1960, the Vienna Convention of 1963 and the Convention on Supplementary Compensation for Nuclear Damage of 1997 - the three most important international conventions on the subject. Finally, the civil liability regime in India will be examined in the light of nuclear damage post to the Civil Liability for Nuclear Damage Act 2010.

\section{The Problem of Liability for Nuclear Damage: Historical Development, Whether the Supplier should be Liable and the Risks of Keeping Operator's Liability Low}

Understanding the broad landscape of nuclear commerce in the world in general and India in particular is very important to fathom the problem of liability for nuclear damage. Nuclear commerce in the world broadly involves two entitles - suppliers and operators. Suppliers such as Areva, Westinghouse and General Electric (GE) are involved in the construction of nuclear reactors, on the other hand, operators such as Nuclear Power Corporation of India Limited (NPCIL) use nuclear reactors to generate electricity and sell it to the grid. Atomic Energy Act 1962 provides that only the Government of India through NPCIL can operate nuclear power plants in India. ${ }^{11}$ Hence, the sole operator NCPIL will operate the nuclear reactors supplied by foreign suppliers to India.

Motivations for Liability Protocols: History of Nuclear Power Development: To understand how the liability protocols associated with nuclear energy have developed over the years, we need look into the history of nuclear power development in the US -world's largest supplier of commercial nuclear power with 104 commissioned nuclear reactors generating $18.9 \%$ of the nation's electric energy (as of 2012). ${ }^{12}$ Since the very introduction of nuclear energy, USA has considerably influenced the development of nuclear law throughout the world to protect its interest. There are two aspects to this analysis - first, cap on total liability of operators and second, indemnity to suppliers from all legal liability. Proponents of nuclear energy justify both of these unusual legislative measures by arguing that there is a crucial national interest in the development of atomic power.

Cap on the Total Liability of Operators: After the Second World War, developed countries of the world were very keen to promote nuclear power to meet their increasing energy needs. However, the electric utilities in the US were investing in nuclear power very reluctantly because of the economic unattractiveness. ${ }^{13}$ The government took many measures to make the nuclear energy market economically viable; one of them being setting up a predictable

\footnotetext{
$11 \quad$ Atomic Energy Act 1962, s 22(1)(a).

12 U.S. Energy Information Administration, 'Monthly Energy Review'

<http://www.eia.gov/totalenergy/data/monthly/pdf/mer.pdf > accessed 28 February 2013.

13 Suvrat Raju, 'The Other Side of Nuclear Liability' (2010) 45 EPW 48, 49.
} 
liability regime. ${ }^{14}$ Since the extent of potential damages from a nuclear accident was magnanimous, the concern of the industry was that compensation claims in the event of a major nuclear accident could easily bankrupt the operator and supplier of the nuclear plant.

Insurance was the traditional option of taking care of such liabilities. However, insurance cover for nuclear liability could not work because of many problems. First, the cost of damage from a nuclear accident had the potential of being immense and beyond the resources of any insurance company. ${ }^{15}$ And second, the hazard posed by nuclear power was entirely new and there was no definite calculation on the probability of occurrence of a nuclear accident.

Taking into account the quantum of potential damages from a nuclear accident and the inability of insurance companies to cover the liability for compensation claims, the US enacted the Price-Anderson Act to channel all economic liability to the operators and fixed a particular amount for the liability, thereby making the government the ultimate insurer in the event of an accident. ${ }^{16}$ It made sense then to put this liability on operators and not suppliers as indeed the operators are the ones involved in handling the nuclear reactors to generate electricity.

Hence, the notion of channelling and limiting the liability of compensation claims arising from a nuclear accident to the operators developed after the realisation that compensation claims that will arise from a nuclear accident would be immense, beyond the capacity of the operators or any insurance company. The government will have to be the ultimate insurer so that victims of a nuclear accident can have a concrete mechanism to have their compensation claims disposed.

Indemnity to Suppliers from all Legal Liability: As the nuclear commerce industry started expanding, the US started to export nuclear power reactors to Europe with which it developed the notion of indemnity to suppliers from all legal liability of a nuclear accident. The European governments were motivated to expand nuclear power but they could not compete with American technology and hence found themselves importing reactors from the US. ${ }^{17}$ Obviously, the American suppliers were apprehensive of bearing liability of an accident in a nuclear plant designed by them in another country. An influential publication called the Harvard Report recommended legislative measures to immunise atomic suppliers from liability claims. ${ }^{18}$

\footnotetext{
14 Lee Clarke, 'The Origins of Nuclear Power: A Case of Institutional Conflict' (1985) 5 Social Problems, 32.

15 DeRoy Thomas, 'Can We Insure against Liability from Nuclear Incidents?' (1958) 1 Cal LR 46, 46.

16 Raju (n 13) 49.

17 Robin Cowan, 'Nuclear Power Reactors: A Study in Technological Lock-In' (1990) 3 Journal of Economic History, 50.

18 Tom Vanden Borre, 'Shifts in Governance in Compensation for Nuclear Damage, 20 Years After Chernobyl' (2007) 21 Tort and Insurance Law, 261.
} 
Hence, the notion of relieving suppliers from liability for nuclear accidents came about to protect the interests of American suppliers exporting nuclear reactors to Europe. The reason put forward was that there will always be an inescapable minute probability of a nuclear accident no matter what, and the compensation claims from such an accident can bankrupt the suppliers.

Supplier's Liability: Why Relieving the Supplier is a Mistake: The notion of immunising the suppliers from liability for accidents has an implicit assumption that the designs made by the suppliers are perfectly safe and that there would not be any design errors that would lead to nuclear accidents. The Kemeny Commission, appointed to investigate the 1978 Three Mile Island accident, put the blame on the design of control room made by suppliers where hundreds of alarms went off in the early stages of accident with no way of identifying the importance ones. Moreover, some key indicators relevant to the accident were on the back of the control panel. ${ }^{19}$ This signifies that even today there could be design errors in nuclear reactors throughout the world that have not been identified yet. This makes the implicit assumption of supplier's immunity very weak.

Indemnifying the suppliers from liability can have very serious consequences. Without liability, there is less motivation for a supplier to design safe nuclear plants. Nuclear reactor designers have multiple constraints. While they would obviously not want a reactor they designed to undergo an accident, they also have to make sure that the design is economical. ${ }^{20}$ If vendors are indemnified against potential claims of safety, their primary aim will then be to get the plant design approved by the regulatory authority that needs to certify the design as being safe. ${ }^{21}$ In terms of legal liability, the supplier's job is done once it has persuaded the regulatory agency, through whatever means, of the safety of the design. Relieving the supplier of liability does not make it economically attractive for a supplier to share new design safety concerns that come to light after commissioning of nuclear plant with the operator or improve the plant.

Cap on Operator's Liability and the Risks in Keeping Operator's Liability Low: The notion of limiting operator liability for nuclear accidents came up because of the realisation that compensating all damages from a nuclear accident is beyond the capacity of operators or any insurance company. Operators are unable to insure the total liability of a nuclear accident in their plants because it is very difficult to estimate the probability of a nuclear accident. For this reason, governments all over the world have limited the operator liability for nuclear plants operating in their country through legislative measures. While in India

19 John Kemeny, 'Report of the President's Commission on the Accident at Three Mile Island' (Kemeny Commission, 30 October 1979) < http://www.threemileisland.org/downloads/188.pdf> accessed 2 March 2013.

$20 \quad$ Raju (n 12) 50.

21 Ibid. 
operator liability has been limited to INR 15 billion there are other countries like the US which have limited operator liability to US $\$ 12$ billion or INR 600 billion. $^{22}$

There are significant risks involved in legislatively decreasing the operator liability. The unofficial estimated death toll after the Chernobyl mishap was 65,000 and damages were worth US $\$ 250$ billion. ${ }^{23}$ As pointed out earlier, even the highest operator liability regimes, as in case of the US, limit liability of operators to trifling amounts as compared to potential damages from a nuclear accident. While it is understandable that an operator may not have the economic strength to cater to compensation claims to the tune of the US $\$ 250$ billion, limiting their liabilities to bread crumbs in comparison to potential damages cannot also be justified. There must be a respectable amount of liability on the operators to make them accountable in nuclear commerce industry. Cap on operator liability serves the purpose of protecting operators from bankruptcy that might result from a nuclear accident, however such protection should not be at the cost of accountability of operators in the nuclear industry.

\section{International Conventions on Civil Liability for Nuclear Damage}

President Eisenhower's famous 'Atoms for Peace' address to the UN General Assembly in 1953 reflects the great optimism surrounding nuclear technology in the early days of nuclear energy. ${ }^{24}$ The International Atomic Energy Agency (IAEA) was established in 1956 to facilitate the nuclear commerce industry. It did not take long for the early optimism and appreciation surrounding nuclear energy to water down when the catastrophic consequences that could follow from failure to maintain adequate level of safety were realised. Such a realisation led to efforts on part of the international organisations to develop competent mechanisms for compensation in case such catastrophic events were to take place. Indeed, these apprehensions were proven true in three series of nuclear accidents: at Three Mile Island, Pennsylvania in 1974, at Chernobyl in 1986 and at Fukushima in 2011. In 1966, Jerry Weinstein summarised the apprehensions as follows:

The principal national and international legal problems posed by the development of the pacific use of atomic energy have been [...] to devise appropriate remedies so that damage to health and property may be compensated in the most humane, equitable and expeditious may possible. ${ }^{25}$

All international liability regimes for nuclear damage share two common features channelling liability to the operator and capping this liability and transferring the final responsibility to compensate the victims to the government. Paris Convention 1960, Vienna

\footnotetext{
22 Anirudh Burman, 'Legislative Brief: The Civil Liability for Nuclear Damage Bill, 2010' (PRS Legislative)<www.prsindia.org/uploads/media/Nuclear/Final\%20Brief\%20\%20civil\%20liability\%20for $\%$ 20nuclear\%20damage\%20bill.pdf $>$ accessed 28 February 2013.

$23 \quad$ Misra (n 1) 31.

24 Dwight Eisenhower, 'Address to $470^{\text {th }}$ Plenary Meeting of the UN General Assembly' (8 December 1953) <www.iaea.org/About/history_speech.html> accessed 1 March 2013.

25 Jerry L Weinstein, 'Progress in Nuclear Energy' (1966) Law and Adm, 9.
} 
Convention 1963 and Convention on Supplementary Compensation for Nuclear Damage 1997 form the core of international law regime on civil liability for nuclear damage. Of these three important instruments, India is a signatory only to the Convention on Supplementary Compensation for Nuclear Damage. ${ }^{26}$ There are substantial advantages for countries with nuclear facilities to be signatories to one or other of these conventions in terms of the legal certainty of liability of its channelling, its limitation of time and its quantum. ${ }^{27}$

Paris Convention on Third Party Liability in the Field of Nuclear Energy 1960: The Paris Convention was negotiated and agreed under the aegis of the Organisation for European Economic Co-operation (OEEC, later known as OECD). The convention was signed in 1960 but it did not come into force until 1968 by when the convention was ratified by five countries. Article 3(a) of the convention provides that the operator of a nuclear installation shall be liable for damage resulting from nuclear accidents at its installation or during the transport of nuclear substances to and from that installation. ${ }^{28}$ The operator is strictly liable regardless of whether fault can be established as opposed to general tort law, which is based on fault or negligence. The convention makes it mandatory for the nuclear installation operator to have financial security equivalent to its liability and fixes a limitation period of 10 years for compensation claims. Article $7(b)$ of the convention provides for a maximum liability of Special Drawing Rights (SDR of the International Monetary Fund) 15 million and a minimum liability of SDR 5 million, i.e. US \$23 million and US \$7.7 million respectively. Inadequacy of compensation amounts was the central weakness of this convention which led to adoption of the Brussels Supplementary Convention 1963 which increased the amount of compensation available under Paris Convention to SDR 300 million, i.e. US \$462 million.

Vienna Convention on Civil Liability for Nuclear Damage 1963: Vienna Convention was negotiated by the IAEA and adopted in 1963, however it did not come into force until 1977 when the necessary five ratifications were achieved. The scheme of Vienna Convention 1963 was by and large similar to that of the Paris Convention as it also made the operator of a nuclear installation strictly liable for damage caused by any nuclear incident. The convention made it mandatory on part of the operator to provide security equivalent to its liability. Article $\mathrm{V}$ of the convention provided that the liability of the operator for any nuclear incident could be limited by national legislation not less than US $\$ 5$ million. The figure was inadequate, though it was possible for countries to set a higher limit. ${ }^{29}$ Even though the compensation amount was recognised as insufficient for proper protection of victims, the minimum liability amount was kept low as a high liability could prevent many

\footnotetext{
26 Status Report, 'Convention on Supplementary Compensation for Nuclear Damage' <http://www.iaea.org/Publications/Documents/Conventions/supcomp_status.pdf > accessed 25 February 2013.

27 Tromans (n 2) 168.

28 Convention on Third Party Liability in the Field of Nuclear Energy <http://www.oecdnea.org/law/nlparis_conv.html> accessed on 2 March 2013.

29 Vienna Convention on Civil Liability for Nuclear Damage <http://www.iaea.org/Publications/Documents/ Infcircs/1996/inf500.shtml> accessed 1 March 2013.
} 
financially poor countries from signing the convention which would have defeated the objective of providing minimum standards of nuclear liability throughout the world. ${ }^{30}$

The Chernobyl nuclear accident of 1986 warned IAEA of the dire need to strengthen the Vienna Convention which proved to be insufficient. This led to adoption of the Protocol to amend the Vienna Convention in 1997 to improve the its regime. Article V of the convention now stands amended making the operator liability not less than SDR 300 million (approximately US $\$ 462$ million). ${ }^{31}$ The limitation period of 10 years for compensation claims under the 1963 version of Vienna Convention has been extended to 30 years by the Protocol.

Convention on Supplementary Compensation for Nuclear Damage 1997: Another step to improve the Vienna Convention regime was adoption of the Convention on Supplementary Compensation for Nuclear Damage 1997. The convention has not come into force yet as it requires ratification by five countries before it can come into force and so far it has been ratified by only four countries. The convention, adopted by IAEA, makes operator liability of at least SDR 300 million mandatory and aims to supplement the Paris and Vienna system of compensation by making public funds available beyond the operator's liability as required by the revised Vienna Convention. The Supplementary Compensation Convention has been described as opening a new chapter in international nuclear law. ${ }^{32}$ Significantly, it is a free standing instrument open to all states, whether nuclear or not and whether a party to the Paris or Vienna Conventions or not. ${ }^{33}$

\section{Civil Liability Regime in India for Nuclear Damage: Scope of Operator and Supplier Liability}

The Civil Liability for Nuclear Damage Act 2010 was passed by the Lok Sabha on August 25, 2010 after fierce debates in the Parliament about what kind of civil nuclear liability regime was to be put in place in India, mostly concerning the scope of operator and supplier liability for nuclear damage. Prior to enactment of the Act, there was no specific law dealing with nuclear liability in India. The preamble of the Act states:

An Act to provide for civil liability for nuclear damage and prompt compensation to the victims of a nuclear incident through a no-fault liability regime channelling liability to the operator, appointment of Claims Commissioner, establishment of Nuclear Damage Claims Commission and for matters connected therewith or incidental thereto.

\footnotetext{
$30 \quad$ Tromans (n 2) 179.

Vienna Convention (n 29).

Ben McRae, 'The Compensation Convention: Path to a Global Regime for Dealing with Legal Liability and Compensation for Nuclear Damage' (1998) Nuclear Law Bulletin 61.

33 Tromans (n 3) 181.
} 
The key issues in the Act are regarding the limit on liability of an operator and the right of recourse of the operator against the supplier. These two focal points have been analysed in the paper.

Liability for Nuclear Damage and Limits: The Act channels all liability to the operator and makes it primarily liable for nuclear damage caused by a nuclear incident. The liability on operator is no-fault and limited. The central government's liability is beyond that of the operator. Of course, the operator has a right to recourse, but such a right can be exercised only after the operator has paid compensation under the Act.

The Act has envisaged a multi-tier compensation system in the event of a nuclear accident. The maximum amount of liability in respect of each nuclear accident has been fixed at rupee equivalent of SDR 300 million (approximately INR 23 billion), however the central government has been empowered to increase this amount by notification. ${ }^{34}$ The liability of the operator is limited to INR 15 billion, a limit which can be set at a higher amount on notification by the central government. ${ }^{35}$ The central government is liable for nuclear damage beyond liability of the operator (INR 15 billion). ${ }^{36}$ Also, the central government is fully and directly liable for nuclear incidents occurring in a nuclear installation owned by it. ${ }^{37}$ Moreover, the central government is empowered to assume full liability for a nuclear installation not operated by it if it is of the opinion that it is necessary in public interest. ${ }^{38}$ The Act makes it mandatory for a nuclear operator, except those installation owned by the central government, to take out insurance policy or other such financial security or combination of both to cover its liability. ${ }^{39}$

When the bill was first introduced in Lok Sabha, the limit on operator's liability was kept at INR 5 billion, however due to the fierce opposition from various political parties and civil society the government raised this limit to INR 15 billion. $^{40}$ The rationale behind making the operator primarily liable is to make sure that victims of a nuclear accident are compensated without delays. The operator has been made liable to pay damages even without fault and has been given the right to recover such amount later if there was no indeed nonfault on part of the operator.

Operator's Right of Recourse: Section 17 of the Act gives the operator of a nuclear plant a right of recourse against the suppliers and other individuals responsible for the damage after having paid the compensation under this Act:

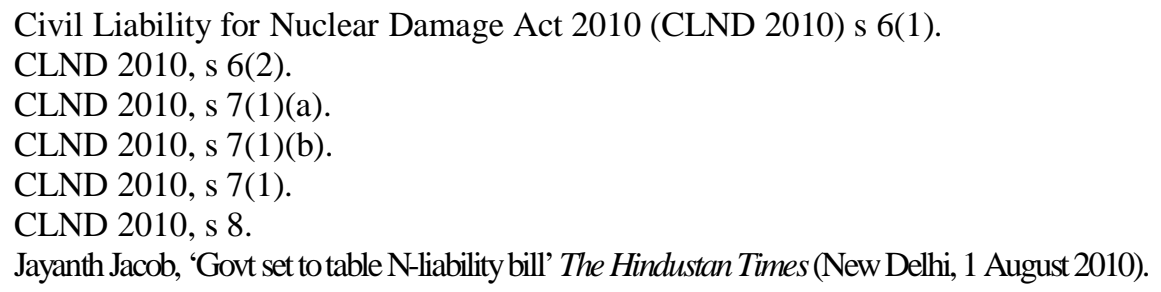


The operator of the nuclear installation, after paying the compensation for nuclear damage in accordance with section 6, shall have a right of recourse where: (a) Such right is expressly provided for in a contract in writing; $(b)$ The nuclear incident has resulted as a consequence of an act of supplier or his employee, which includes supply of equipment or material with patent or latent defects or sub-standard services; (c) The nuclear incident has resulted from the act of commission.

Operator's right of recourse, specifically against the supplier under clause (b) is perhaps the most controversial part of the Act and has stalled the passage of this law in Indian Parliament for months. The confrontation between the ruling and opposition parties on this Act was primarily focused on the scope and extent of operator's right of recourse against the supplier. All major international agreements on civil liability for nuclear damage provide for a right of recourse against the person actually causing damage only if there is a written contract or if the damages result from an act or omission of someone with intent to cause damage. ${ }^{41}$ Most countries do not provide a right of recourse against the supplier, and even those that do, restrict it to cases of wilful act or omission. While the government wanted to dilute the right of recourse against the supplier, the opposition vehemently opposed such measures.

Moving away from international conventions and best practices, the Act provides an additional ground of recourse from the supplier if the nuclear incident has resulted as a consequence of equipment or material with patent defects (defects discoverable by inspection) or latent defect (defects that cannot be discovered by a reasonably thorough inspection) or substandard services supplied by the supplier. Naturally, this expansion of operator's right of recourse has not been received well by the foreign and domestic suppliers who want to enter the fast growing Indian nuclear market. ${ }^{42}$ To allay the apprehensions of the suppliers who would have found it very difficult to engage in nuclear trade in India if their liability was not relieved, the government watered the right of recourse down to some extent in the rules notified under the Act. ${ }^{43}$ Rule 24 of Civil Liability for Nuclear Damage Rules 2011 clarifies the right of recourse as provided in the Act:

(1) A contract referred to in clause (a) of section 17 of the Act shall include a provision for right of recourse for not less than the extent of the operator's liability under sub-section (2) of section 6 of the Act or the value of the contract itself, whichever is less. (2) The provision for right of recourse referred to in sub-rule (1) shall be for the duration of initial license issued under the Atomic Energy Rules, 2004 or the product liability period, whichever is longer. Explanation 1 - For the

41 Burman (n 22).

42 Siddharth Varadarajan, 'India resists U.S. pushback on nuclear liability' The Hindu (Chennai, 22 October 2010).

43 Pranab Dhal Samanta, 'N-liability law: 'Meeting supplier's midway', Govt may fix time and cost' The Indian Express (New Delhi, 28 December 2010). 
purposes of this rule, the expressions, "Product liability period" means the period for which the supplier has undertaken liability for patent or latent defects or substandard services under a contract...

The notified rules bring in a possible way around the practical hurdles posed by the recourse from supplier clause in the Act by making it clear that a supplier will be liable only for a fixed time period and not for the entire lifetime of a reactor. Such a period can be negotiated by the supplier in the contract. The rules make it clear among other things that there would be no unlimited or unending liability on part of the suppliers. The suppliers of the nuclear material to nuclear power plants would not be held liable for accidents caused by defective or faulty equipment supplied by them if the accident takes place after a guarantee period specified by them.

Even then, the right of recourse against the supplier as provided in section 17(b) should make the suppliers accountable in nuclear accidents and take care of the risks involved in relieving suppliers of liability as has been discussed previously. This is a positive step and the Indian Parliament should be applauded for making suppliers accountable in Indian nuclear market.

\section{Conclusion}

Nuclear energy has seen tremendous growth in the last two decades, riding mostly on the growing concern in international community about global warming. Negligible carbon emission is perhaps one of the strongest arguments in favour of nuclear energy. But there is another sad reality to nuclear energy that was evident in the three series nuclear accidents at Three Mile Island in 1974, at Chernobyl in 1986 and at Fukushima in 2011. The magnanimous damages that are caused in a nuclear accident make it imperative to put a concrete mechanism in place to deal with compensation claims. All international liability regimes for nuclear damage share two common features - channelling liability to the operator and capping this liability and transferring the final responsibility to compensate the victims to the government. Relieving the supplier from all liability of a nuclear accident carries with itself high risks, essentially leaving less incentive for the supplier to design safer nuclear plants.

In the Indian civil nuclear liability regime, apart from channelling liability to the operator, capping this liability and transferring the final responsibility to compensate the victims to the government, the operator has been given a right of recourse against the supplier if the nuclear incident has resulted as a consequence of equipment or material with patent defects or latent defect or substandard services supplied by the supplier. It is indeed a substantial departure from the international best practices but this departure is more than justified as it makes suppliers accountable in nuclear commerce and minimises the risks of relieving supplier from all liabilities.

$* * * * * * * * * * * * * * * * * * *$ 